\section{Diagrama de flujo para la evaluación de Programas de Postítulo para la formación de especialistas en Medicina}

\section{Flow sheet to evaluate Post Graduate Teaching Programs in Medicine}

\section{Sr. Editor:}

En una carta previa ${ }^{1}$ propusimos un diagrama de flujo para la evaluación y autoevaluación de Programas de Postítulo para la formación de Especialistas en Medicina, la que fue corregida por el Dr. Vicente Valdivieso, Secretario Ejecutivo de la Agencia Acreditadora de Programas y Centros Formadores de Especialistas Médicos (APICE)2. Dicho diagrama ha debido mutar de acuerdo a los cambios que ha sufrido la legislación sobre acreditación. En particular, hay dos cambios que son los más relevantes y se refieren a la no interferencia de la acreditación en la autonomía universitaria:

1) Acreditación limitando el número de residentes.

2) Limitación por el método de financiamiento de los alumnos.

Desde abril de 2012 y por decisión de la Comisión Nacional de Acreditación (CNA), se prohibió a las agencias establecer en sus acuerdos cupos numéricos de alumnos (Dr. Vicente Valdivieso, comunicación personal, octubre de 2014).

En este sentido, los pares evaluadores de las agencias acreditadoras (por ejemplo: APICE), pueden opinar en su informe final sobre si el número de alumnos matriculados anualmente por la institución que postula a ser evaluada es concordante o no con su capacidad formadora y de supervisión, pero sin tener injerencia en el número máximo o eventual incremento en el número de residentes que pudiese tolerar un programa. Queda establecido así que las agencias acreditadoras no serán un factor limitante en este aspecto.

Con respecto a la capacidad de financiamiento de los residentes, es muy deseable que todas las becas tengan financiamiento y no existan alumnos autofinanciados, lo que se comprueba al analizar los criterios para lograr acreditarse por el máximo de tiempo un programa de especialidad. Si bien no es requisito para acreditarse, es hacia donde un buen programa debe orientarse, ya que permite a los alumnos centrarse en su formación sin necesidad de distraerse en generar recursos monetarios con actividades remuneradas fuera del programa de formación.

Con estas consideraciones, el diagrama de flujo propuesto sigue siendo válido, aunque algunos aspectos que impedían seguir adelante sólo son modificadores en el número de años que eventualmente será acreditado el programa, si cumple con los otros aspectos obligatorios, por lo cual se ha modificado parcialmente la Figura.

- Las primeras 4 cajas son de carácter obligatorio. Si una de ellas falta, no se puede seguir avanzando. Nótese que todo programa debe estar respaldado por una Universidad.

- Las siguientes cajas son muy deseables que estén. Cada comisión debe definir los estándares umbrales, de acuerdo a las directrices de APICE o la que corresponda en su momento. Su presencia determina el número de residentes y de años por el cual se acreditará el programa.

- Las cajas con asterisco determinan algunos de los criterios para acceder al máximo de tiempo de acreditación.

Figura. Diagrama de flujo para la interpretación de los estándares de acreditación de postítulos para la formación de Especialistas en Medicina (ver Referencia 1).

Héctor J. Lacassie ${ }^{1}$, Ana María Espinoza $U^{2}$ ${ }^{1}$ Profesor Asociado. División de Anestesiología, Facultad de Medicina, Pontificia Universidad Católica de Chile. Santiago, Chile. ${ }^{2}$ Profesor Asociado. Departamento de Anestesiología, Facultad de Medicina, Universidad de Chile. Santiago, Chile.

\section{Referencias}

1. Lacassie H, Espinoza A, Concha M. Diagrama de Flujo para la Evaluación de Programas de Formación de Postgrado. Rev Med Chile 2011; 139 (7): 961-2.

2. Valdivieso V. Evaluación de Programas de Formación de Postgrado en Chile. Rev Med Chile 2011; 139 (11): 1516.

Correspondencia a:

Héctor J. Lacassie

hlacassie@gmail.com 